\title{
Success Factors for PDCA as Continuous Improvement Method in Product Development
}

\author{
Eirin Lodgaard $^{1,2}$, Inger Gamme ${ }^{3}$, and Knut Einar Aasland ${ }^{1}$ \\ ${ }^{1}$ Norwegian University of Science and Technology, Trondheim, Norway \\ knut.e.aasland@ntnu.no \\ ${ }^{2}$ SINTEF Raufoss Manufacturing, Raufoss, Norway \\ eirin.lodgaard@sintef.no \\ ${ }^{3}$ Gjøvik University College, Gjøvik, Norway \\ inger.gammeahig.no
}

\begin{abstract}
In order to maintain sustainability in an ever changing environment, where customer requirements contains a yearly price reduction over the life cycle of a product, decreased time for development of new products and increased product quality, there is an increased need for focus on continuous improvements. A well-known improvement method is the PDCA (Plan-DoCheck-Act), which many companies have succeeded in implementing in the manufacturing department. Not so common, is the use of this method for the development process. The aim of this article is to present success factors which must be in place to succeed in using the specified method, and thereby the desired improvement during continuous improvement initiatives within product development. Management commitment is ranked as most important followed by knowledge about how to use the method, when to apply PDCA, efficient performance and use of internal marketing activities to focusing on the topic.
\end{abstract}

Keywords: Automotive supplier industry, product development, continuous improvement, PDCA.

\section{Introduction}

The long term business sustainability in the automotive supplier industry depends on the ability to face demanding customer requirements. Requirements of a yearly price reduction over the life cycle of a model, decreased time for development of new products and increased requirements and expectations of continuous development of better products and processes for the future are typical for the automotive industry. This requires that companies in the automotive supplier industry continuously improve in all functions of the company, including product development (PD). At least $80 \%$ of the life cycle cost of a product is determined in the early phase of PD. This indicates the importance of how the PD is performed with regards to continuous improvement[1].

Today there are several types of continuous improvement methods in use in the automotive supplier industry, such as LAMDA (Look-Ask-Design-Model)[2], Six 
Sigma[3] and PDCA (Plan-Do-Check-Act)[4, 5]. This research project has chosen to study the PDCA method because it is highly recommended as continuous improvement method in the automotive industry, outlined in the quality standard, ISO/TS 16949[6]. Many companies have successfully implemented the PDCA method in the manufacturing department, but for the future it is important to include the product development as well to be competitive in this demanding industry.

The aim of this paper is to identify success factors when using the established continuous improvement method PDCA, in product development. What success factors must be in place to succeed in using the specific method to achieve the desired improvements during continuous improvement initiative?

\section{Continuous Improvement in Product Development}

Continuous improvement has been in focus in the automotive industry for several decades. It is important to have a never-ending process of performance improvements to gain effective processes in product development [7]. Several companies have succeeded implementing systematic continuous improvement in manufacturing, but few have succeeded in PD. Although many "kaizen" or continuous improvement initiatives are started, the failure rate is high[8]. Lillrank et al reported that two out of three continuous improvement initiatives fail to deliver the desired improvement[9]. This shows the importance of finding out why the failure rate is high and what factors must be in place for successful implementation of continuous improvement in a complex and turbulent environment, such as product development.

\section{PDCA as a Continuous Improvement Method}

In 1950 W. Edwards Deming was invited to Japan by the Union of Japanese Scientist Engineers to teach statistical quality control. He arranged seminars together with manager, focusing on the connection between quality and productivity and the use of statistical process control. He also introduced the Deming wheel which emphasized the importance of constant interaction among research, design, production, and sales to assure better product quality and satisfied customers. The Japanese developed it further to be applied in all problem solving situation and called it PDCA [10]. The PDCA method has been used ever since by the Japanese industry as a systematic continuous problem solving approach. Western industry started to focus on development and implementation of continuous improvement processes in the beginning of the 1980s [11]. Today, this tool is widely outspread in the manufacturing industry and the PDCA is highly recommended in the quality assurance standard ISO/TS 16949 used by the automotive supplier industry.

The PDCA method includes four phases: Plan, Do, Check and Act. The phases are defined in different versions in the literature, but with the same purpose, to continuous improve. We have divided the four phases into seven steps, as shown in figure 1. It starts with identifying the current situation and target for the improvement. Thereafter, to dig deep into the details to discover root causes to avoid jumping to solutions. 
After implementation of the actions it is important to study and evaluate the results and if necessary go back to prior phases and modify solutions. The final step is to ensure that the improved level of performance is maintained and to capture what is learned during each of the phases in the PDCA cycle.

Today, the PDCA method is primarily applied in the manufacturing department and less applied in the product development. In manufacturing of a physical product, it is easier to implement the method. In addition, the manufacturing staff is more easily manageable than in the innovative and creative environment of product development. In product development, it is necessary to find a balance between formal processes and creative freedom in order to succeed with continuous improvement.

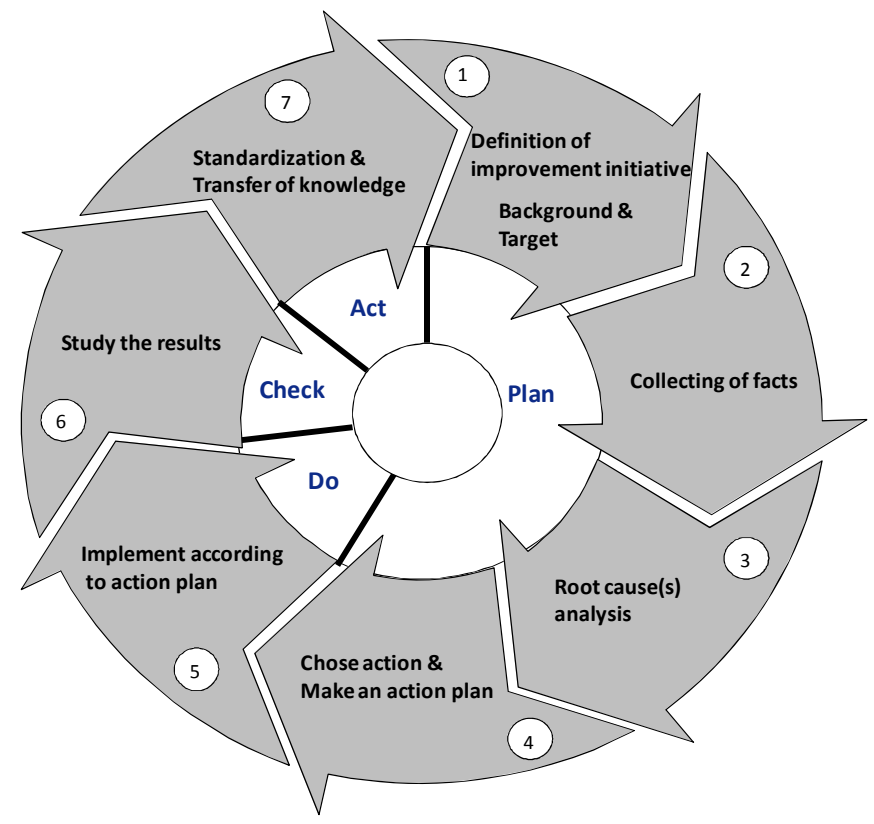

Fig. 1. PDCA

\section{Case Company and Research Method}

The following section outlines the case company and the research approach used to conduct this study. The case company is a Norwegian automotive supplier with customers on a worldwide basis. The automotive supplier industry was chosen as a case since they already have a formal requirement, based on ISO/TS 16949, to define a continuous improvement method and to apply the method to assure continuous improvement in the entire company. The chosen case company has a Quality Assurance system, where the PDCA method is chosen to be implemented in the entire organization. They have long experience with continuous improvement methods primarily in the manufacturing department; therefore it is interesting to investigate the product 
development area and the main critical success factors for successful implementation of the PDCA method.

The research method is based on an extension of the action research approach. The action research is on application of the PDCA method in continuous improvement projects in product development. After finishing several continuous improvement projects in the action research, with the purpose to get experience with PDCA, a brain writing workshop was performed with the aim of defining the success criteria for application of PDCA. The same team participated in both the improvement projects and the brain writing workshop. The participants were professionals from the field of management, simulation, calculations, process and product development, quality assurance and research. Brain writing is a silent, sharing, written creativity method and does not involve group discussion of written ideas during the idea-generation session[12].The brain writing method applied was the $6 \times 3 \times 5$ method, which uses the principle: 6 participants writing down 3 ideas in 5 minutes. Each participant starts with writhing down three ideas on a sheet of paper before sending the paper on to person seated on his right-hand side. The next step was to complement ideas on the received sheet. This was continued until the sheets were passed through all participants.

\section{Success Factors for Use of PDCA}

This chapter outlines the results from the brain writing workshop based on the extended action research project with focus on application of PDCA. Table1 summarizes the results from the brain writing workshop with the main success criteria when using PDCA in product development. These main factors have been grouped into five categories, after a coding and analyzing process[13]. The first result in the table was ranked as the most important factor and the last one as less important in the brain writing workshop. The listed factors are: management commitment, knowledge on how to use PDCA, when to apply the method, efficient performance and, internal marketing activities. Each participant picked out the three most important ideas which are shown in the table as subgroups. Each success factor and its subgroup factors will be presented more in-depth.

\subsection{Management Commitment}

Management commitment is ranked as the most important factor in succeeding with your continuous improvement initiatives based on the PDCA method. One possible explanation for this result is that people tend to prioritize the work that the management team wants them to perform. It is not easy to stay motivated working on topics nobody asks for. Imai stated that continuous improvement is the most dominant concept behind good management [10]. Bessant et al. stated that the management is a key variable to maintain the continuous improvement behavior patterns but that is often poorly understood by themselves [14]. The use of PDCA must be included in the strategy to show that the management really wants to apply the PDCA method. This will help the company to sustain the use of the PDCA method, especially if the management also uses the method. 
Table 1. Success factors when applying PDCA

\begin{tabular}{|c|c|c|}
\hline Main Success factor & Subgroup & $\begin{array}{l}\text { Number of feasible } \\
\text { and relevant ideas }\end{array}$ \\
\hline Management Commitment & $\begin{array}{l}\text { - Walk like you talk } \\
\text { - Engagement } \\
\text { - Sustainability } \\
\text { - Included in the strategy }\end{array}$ & 20 \\
\hline $\begin{array}{l}\text { Knowledge on how to use } \\
\text { PDCA }\end{array}$ & $\begin{array}{l}\text { - Education } \\
\text { - Training of practical use } \\
\text { - Knowledge on how to use } \\
\text { PDCA in the entire organ- } \\
\text { ization } \\
\text { - Training included in the } \\
\text { budget }\end{array}$ & 22 \\
\hline When to apply PDCA & $\begin{array}{l}\text { - Predefined which type of } \\
\text { continuous improvement } \\
\text { project }\end{array}$ & 6 \\
\hline Efficient performance & $\begin{array}{l}\text { - A time efficient method } \\
\text { - PDCA method applied as } \\
\text { simple as possible } \\
\text { - Use of PDCA must be a } \\
\text { choice in their existing "to } \\
\text { do list" }\end{array}$ & 11 \\
\hline $\begin{array}{l}\text { Internal marketing activi- } \\
\text { ties }\end{array}$ & $\begin{array}{l}\text { - Use of intranet in general } \\
\text { - Publishing of implemented } \\
\text { PDCA } \\
\text { - Specialist continuous mar- } \\
\text { keting the method } \\
\text { - Hang up a notice (A3) in } \\
\text { the office area }\end{array}$ & 13 \\
\hline
\end{tabular}

\subsection{Knowledge on How to Use PDCA}

Not surprisingly, the results from the brain writing workshop shows that the entire organization must have performed education in the PDCA method as well as further training in practical use. Educational actions in order to get knowledge about the method are essential to be able to perform continuous improvement initiatives based on PDCA [15]. A firm competitive is not so much production equipment but rather what it knows and how it behaves [8]. Ishikawa stated that continuous improvement starts with education and ends with education [16]. This is supported by Caffyn who 
found that lack of training is an inhibiting factor for extending continuous improvement to the new product development process [17]. Finding from the study done by Yan and Makinde shows that management must prioritize training opportunities to all employees to assure that they really understand what continuous improvement is about [18]. This is substantial to be able to apply the method in a time efficient way as the intention of PDCA is.

\subsection{When to Apply PDCA}

When to apply PDCA is not clearly identified [8]. Not all continuous improvement initiatives require use of PDCA, however purposeful improvement in large or complex systems will be appropriate to use PDCA [15]. Common understanding about when to apply the method could be an advantage in order to avoid frustrated employees that do not know what type of continuous improvement initiatives they shall apply the PDCA method on. This will probably be more clarified when the organization has used the PDCA for a while. When you got more experience, then you know when the PDCA can be efficiently applied or not. The dedicated project team in this research study had performed some continuous improvement projects by applying PDCA. In spite of this it was not sufficient to have an overview of when to apply PDCA.

\subsection{Efficient Performance}

Today it is several definitions in the literature of the four phases of PDCA, all with the purpose to assure continuous improvement and problem solving. It is important for organizations to clearly define the concept together with well prepared and user friendly templates. The western companies is known as too fast to conclude on solutions therefore it is important to define the first phase clearly and to secure enough time to collect data to achieve fact based solutions [5].

\subsection{Internal Marketing Activities}

The use of intranet, or similar type of mediums, in order to communicate the results from previous improvement projects to the affected part of the organization, is among the participants, defined as an important topic. Use of internal marketing activities to make a clear and credible plan for the organization together with demonstrated results from continuous improvement initiative are essential element in motivating people and to grow culture for continuous improvement [10]. Communication about where the company is heading and how it will get generally make people more enthusiastic about the improvement process. This may indicate that visualization of results from continuous improvements, which must be common for all affected employees, is important to drive successful improvement projects. In a study done by Caffyn and Grantham the results show that all companies studied lacked a strategic approach to the development of continuous improvement, and to capture, share and deploy learning from the improvement [19]. Many people have difficulties sharing knowledge across the team and sometimes even with people in the team. Internal marketing 
activities can make the knowledge more accessible to others, enable reuse of the knowledge they have, and make it more accessible for others. Capturing and sharing knowledge created is important in delivering high quality products [20].

\section{Concluding Remarks}

Based on action research and a brain writing workshop, involving one of the development teams, we have identified the main success factors and their subgroups to be able to succeed using PDCA in product development. From observations in our study we can propose five aspects which are essential to be aware of if you want to implement the specified improvement method PDCA, in product development. The first, and the most important one, is the commitment by the management. This aspect is of importance to be able to establish the method as a standardized improvement method. As a strategy to solve continuous improvement initiatives, PDCA must be included by the management as method, which they are using in their daily work for the suggested purpose. When to use the defined improvement method, combined with sufficient competence of how to use the method, are the next two success factors. The fourth aspect is to ensure efficient ways to perform the method, such as use well prepared user-friendly templates, with a thought-through common way to perform the improvement issues. The last aspect is to ensure an internal marketing of the application of PDCA method, with specific results from implemented improvement initiatives to show the efficiency of using PDCA. This will contribute on the sustainability of uses of the method if people can see the profit by use of PDCA.

\section{References}

1. Ragatz, G.L., Handfield, R.B., Scannel, T.V.: Success Factors for Integrating Suppliers into New Product Development. Journal of Product Innovation Management 14, 190-202 (1997)

2. Ward, A.C.: Lean Product and Process Development. Lean Enterprise Institute, Cambridge (2007)

3. Bicheno, J., Catherwood, P.: Six Sigma and the Quality Toolbox. Picsie Books, Buckingham (2005)

4. Shook, J.: Managing to Learn. Using the A3 Management Process to Solve Problems, Gain Agreement, Mentor, and Lead. The Lean Enterprise Institute, Cambridge (2008)

5. Sobek, D.K., Smalley, A.: Understanding A3 Thinking, A Critical Component of Toyota's PDCA Management System. Productivity Press, New York (2008)

6. ISO/TS 16949:2009: Quality Management System: Particular Requirements for the Application of ISO 9001:2008 for Automotive Production and Relevant Service Part Organization (2009)

7. Morgan, J.M., Liker, J.K.: The Toyota Product Development System, Integrating People, Processes and Technology. Productivity Press, New York (2006)

8. Bessant, J., Caffyn, S., Gallagher, M.: An Evolutionary Model of Continuous Improvement Behavior. Technovation 21, 67-77 (2001) 
9. Lillrank, P., Shani, A.B.R., Lindberg, P.: Continuous Improvement: Exploring Alternative Organizational Designs. Total Quality Management 12, 41-55 (2001)

10. Imai, M.: Kaizen. The Key to Japan's Competitive Success. Random House, New York (1986)

11. Nilsson-Witell, L., Antoni, M., Dahlgaard, J.J.: Continuous Improvement in Product Development. The International Journal of Quality \& Reliability Management 22, 753-768 (2005)

12. Heslin, P.A.: Better than Brainstorming? Potential Contextual Boundary Conditions to Brainwriting for Idea Generation in Organizations. Journal of Occupational and Organizational Psychology 82, 129-145 (2009)

13. Miles, H., Hubermann, M.: Quality Data Analysis: A sourcebook. Sage Publications, Beverly Hills (1994)

14. Bessant, J., Caffyn, S., Gallagher, M.: An Evolutionary Model of Continuous Improvement Behaviour. Technovation 21, 67-77 (2001)

15. Langley, G.J.: The improvement Guide. A practical Approach to Enhancing Organizational Performance. Jossey-Bass, San Francisco (2009)

16. Ishikawa, K.: What is Total Quality Control? The Japanese Way. Prentice Hall, Englewood Cliffs (1985)

17. Caffyn, S.: Extending Continuous Improvement to the New Product Development Process. R \& D Management 27, 253-253 (1997)

18. Yan, B., Makinde, O.D.: Impact of Continuous Improvement on New Product Development within SMEs in the Western Cape, South Africa. African Journal of Business Management 5, 2200-2229 (2011)

19. Caffyn, S., Grantham, A.: Enabling Continuous Improvement of New Product Development Process. Industry and Higher Education 14, 235-243 (2000)

20. Radeka, K.: Lean Product Development at Playworld System. Target Magazine 27, 10-17 (2011) 